\title{
EVALUATION OF THE PERFORMANCE OF BIOSPHERE COMPATIBLE CITY FUNCTIONS IN MODERN RESIDENTIAL AREAS
}

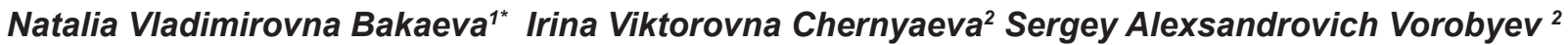 \\ ${ }^{1}$ Southwest State University, Kursk, Russia \\ ${ }^{2}$ Orel State University, Orel, Russia
}

The article discusses the issues of city construction policy in the field of urban infrastruc-ture planning, design and construction of modern residential areas from the perspective of city and settlement biosphere compatibility. The authors propose a technique for calculating gener-alized criteria for the biosphere compatibility of urban environment; give systematized constitu-ents of city infrastructure when evaluating the performance of city functions in modern residential areas. The gradation of the levels of performance and availability coefficients is carried out. The developed technique is an integral part of the methodology for urban infrastructure development planning. Numerical performance of the biosphere compatible city functions is shown; its analysis is carried out based on the data of one of the new residential areas of a large Russian city. The authors come to the conclusion concerning the fundamental necessity of adopting a new innovation city planning policy.

Key words: Urban infrastructure planning, Biosphere compatible city, Bio-technosphere balance, City functions, Performance, Availability

\section{INTRODUCTION}

In the conditions of an unfavourable ecological situation, significant transformations in the economy and social sphere peculiar to many cities of Russia and the world as a whole, it is expedient to implement the city planning policy in the field of urban infrastructure planning, resi-dential areas design and construction on a qualitatively new basis. In this case, it is possible to carry out regulatory, legal, organizational, economic, and environmental support for construction applying fundamental principles of the paradigm of biosphere compatibility of cities and settle-ments [01, 02].

\section{PROBLEMS OF}

The paradigm of biosphere compatibility of cities and settlements is proposed by the Russian Academy of Architecture and Construction Sciences and requires the necessity of es-tablishing a balance between the elements of technosphere and biosphere potential to be pro-vided; this will result in the territorial preservation and restoration of the natural environment and, at the same time, in the development of a human being as its integral part. Based on the proposed paradigm, urban planning policy can also be formed [03]; ecophilosophical approach to the development of modern cities and the creation of the conditions for urban areas develop-ment is used as the foundation of the paradigm.

With regard to evaluating the state of urban infrastructure and modern residential areas as its integral part, one of the key tasks is the development of the generalized criteria reflecting biotechnosphere balance within the boundaries of a certain urban area. This problem can be solved by constructing integral indicators:
- performance of the biosphere compatible city functions $\xi$;

- biosphere compatibility of the territories of objects $\eta$, proposed in [04].

The studies using these generalized indicators are devoted to the possibility of the quantitative evaluation of the level of performance of city functions by means of the design solu-tions of a residential district as an example. The results obtained allow predicting the develop-ment of the area from the perspective of its biosphere compatibility. Let us consider this problem in detail.

To evaluate the performance of biosphere compatible city functions through its transport constituent, a technique for calculating generalized criteria of evaluating the state of urban environment was developed; an appropriate aggregated estimation of the performance of all city functions without exception was carried out [05]. These studies were based on the hy-pothesis that all the functions of a biosphere compatible city are equisignificant in their im-portance. Based on these prerequisites for the calculation of the indicator of their performance, the following formula is proposed [06]:

$$
\xi=\sum^{n} \xi_{\Phi_{n}}=n \cdot \xi_{\Phi_{n}}
$$

where $\xi_{\Phi_{n}}$ is the $\Phi_{n}^{\text {th }}$ city function; $n$ is the number of city functions, accepted when evaluating.

The indicator of the performance of a specific $\Phi_{n}{ }^{\text {th }}$ city function $\xi_{\Phi_{n}}$ can be determined by the formula:

$$
\xi_{\Phi_{n}}=\sum_{i=1}^{i=i} c_{i n} \alpha_{i n} \beta_{\text {in }} / \sum_{i=1}^{i=i} c_{i n}^{*} \alpha_{i n}^{*} \beta_{i n}^{*}
$$


where $c_{i n}$ is the relative value of the $i^{\text {th }}$ constituent in the $\Phi_{n}^{\text {th }}$ city function per one city dweller; $\alpha_{i n}$ is the availability coefficient of the $i^{\text {th }}$ constituent; $\beta_{\text {in }}$ is the performance coefficient of the $i^{\text {th }}$ constituent; $c_{\text {in }}$ is the minimum essential relative value of the parameter from the point of view of human development in a biosphere compatible city; $\alpha_{i n}^{*}$ is the normalized (maximum possible or rational) value of the availability coefficient; $\beta_{i n}^{*}$ is the normative (established by the regulations, guaranteed by the legislation and administration of the settlement, imposed by market relations, rational or the best calculated) value of the performance indicator $\beta_{\text {in }}$.

Taking into account that in the current regulations of spatial planning not all the param-eters included in formula (2) can be normalized, we assume that for the possibility of numerical performance all the $i^{\text {th }}$ constituents of each $\Phi_{n}{ }^{\text {th }}$ biosphere compatible city function are also equisignificant and equal to the value determining the human development index:

$$
c_{i n}^{*}=c_{i n}=1 / i_{n}
$$

As a result, formula (2) takes the form:

$$
\xi_{\Phi_{n}}=\sum_{i=1}^{i=i} \alpha_{i n} \beta_{i n} / \sum_{i=1}^{i=i} \alpha_{i n}^{*} \beta_{i n}^{*}
$$

and the indicator of the performance of biosphere compatible city functions $\xi$ can be determined on the basis of the expression:

$$
\xi=\sum_{n=1}^{n=n} \sum_{i=1}^{i=i} \alpha_{i n} \beta_{i n} / \sum_{n=1}^{n=n} \sum_{i=1}^{i=i} \alpha_{i n}^{*} \beta_{i n}^{*}
$$

It is easy to see that the values of the indicators $\xi, \xi_{\Phi}$ are in the range of $0 \leq \xi \leq 1 ; 0 \leq \xi_{\Phi_{n}} \leq 1 / n$. In this case, the maximum possible values of the parameters $\alpha_{i n}, \alpha^{*}{ }_{i n}, \beta_{i n}, \beta_{i n}^{*}$ are:

$$
\xi_{\Phi_{n}, \max }=\sum_{i=1}^{i=i} \alpha_{i n}^{\max } \beta_{i n}^{\max } / \sum_{i=1}^{i=i} \alpha_{i n}^{*}{ }^{, \max } \beta_{i n}^{*, \max }=1 / n
$$

Parameters $\alpha_{i n}, \beta_{\text {in }}$ reflect current, actual indicators, and $\alpha_{i n}^{*}, \beta_{i n}^{*}$ reflect normative, i.e. minimum required from the point of view of human development or rational, the maximum possible values of which are equal to 1 . This assumption is fair because when introducing $\alpha_{i n}^{*}<1, \quad \beta_{i n}^{*}<1$ into the calculation, the effect of an unjustified increase in parameter $\xi_{\Phi_{n}}$ is observed.

Thus,

$$
\sum_{i=1}^{i=i} \alpha_{i n}^{\max } \beta_{i n}^{\max } / i_{n}=1 / n \quad \text { or } \quad \alpha_{i n}^{\max } \beta_{\text {in }}^{\max }=1 / n
$$

The same prerequisites can be used to evaluate the performance of the biosphere compatible city functions for residential districts.
Then, within the framework of the accepted hy-pothesis on the equivalence of city functions and the contribution of their constituents to the performance of the functions for numerical analysis, we assume that $\alpha_{i n}^{\max }=\beta_{i n}^{\max }$. Then $\alpha_{i n}^{\max }=\beta_{i n}^{\max }=1 / \sqrt{n}$.

In turn, the values $\alpha_{i n}=1 / \sqrt{n}, \beta_{i n}=1 / \sqrt{n}$, correspond to the normative level $\left(\alpha_{i n}^{*}=1, \beta_{i n}^{*}=1\right)$.

On the basis of the same assumption, the grading of the levels of the evaluated coefficients is carried out: performance $\beta_{\text {in }}$ according to the availability (in principle) and the quality of performance and $\alpha_{\text {in }}$ according to spatial, temporal and personal availability.

Performance $\beta_{\text {in }}$ without regard to quality: total absence of performance is 0 ; perfor-mance equal up to $25 \%$ is $0.25 / \sqrt{n}$; performance equal up to $50 \%$ is $0.50 / \sqrt{n}$; performance equal up to $75 \%$ is $0.75 / \sqrt{n}$; $100 \%$ performance is $1 / \sqrt{n}$.

Performance $\beta_{i n}=\beta_{i n}^{1}+\beta_{i n}^{2}$ with the evaluation of characteristics $\beta_{\text {in }}^{1}$ total absence of performance is 0 ; performance equal up to $25 \%$ is $0.175 / \sqrt{n}$; performance equal up to $50 \%$ is $0.35 / \sqrt{n}$; performance equal up to $75 \%$ is $0.525 / \sqrt{n} ; 100 \%$ performance is $0.70 / \sqrt{n}$ and $\beta_{\text {in }}^{2}$ : low quality is 0 ; satisfactory quality is $0.1 / \sqrt{n}$ good quality is $0.2 / \sqrt{n}$; high quality is $0.3 / \sqrt{n}$.

Availability $\alpha_{i n}=\alpha_{i n}^{1}+\alpha_{i n}^{2}+\alpha_{i n}^{3}$ with the full evaluation of the characteristics. Spatial availability $\alpha_{\text {in }}^{1}$ : no spatial availability is 0 ; spatial availability is possible, but it is prohibited $-0.1 / \sqrt{n}$; spatial availability is limited $0.2 / \sqrt{n}$ spatial availability is unlimited $-0.4 / \sqrt{n}$. Time availability $\alpha_{i n}^{2}$ : time availability is limited permanently 0 ; time availability is limited $-00.2 / \sqrt{n}$; time availability is unlimited $-0.3 / \sqrt{n}$. Personal availability $\alpha_{i n}^{3}$ : no availability for all sections of population -0 ; availability is limited, available not for all the sections of population $0.1 / \sqrt{n}$; availability is limited, possible for all the sections of population $-0.2 / \sqrt{n}$; a for all the sections of population $-0.3 / \sqrt{n}$.

A simplified version of availability $\alpha_{\text {in }}$ evaluation is possible; it is carried out as follows: not available is 0 ; availability is limited $-0.1 / \sqrt{n} \div 0.9 / \sqrt{n}$; full availability $-1 / \sqrt{n}$.

\section{RESULTS}

Let us consider the numerical performance of biosphere compatible city functions by the example of a new residential district in Russia (the city of Orel). The expert opinion on the state of the district infrastructure is a methodological basis for the quantitative evaluation of the performance of city functions.

The residential district provides for a street-road network as part of the existing urban networks. Currently, the system of regular public transport is organized. Within the district, there are open parking lots and garages within pedestrian accessibility of not more than 800 meters. Next to the building site there is a motor-racing track and a petrol station. 
Moreover, the project provides for the following infrastructure facilities on the territory of the new residential district: a shopping center, 5 kindergartens (three ones for 330 children and two ones for 280 children), two schools (for 1,728 and 1,296 schoolchildren), a sports facility, a summer cafe, a bathhouse, a fire station, and two multi-level garages.

During the construction of houses, the surrounding grounds are being landscaped: lawns, trees and shrubs are being planted; small playgrounds with hard landscaping, coating driveways and pavements with asphalt, arrangement of open guest parking lots and places for people's recreation are being carried out (Figure 1).

Thus, according to the development master plan, natural landscapes necessary for neutralizing emissions and normalizing the ecological situation in the residential district will be maximally preserved during the construction. The systematized contribution of the specific constituents of the district infrastructure to the performance of biosphere compatible city functions based on the project solutions is shown in Table 1.

For the system of the constituents proposed in Table 1: $n=7,0 \leq \xi_{\Phi_{n}} \leq 1 / 7$, and taking into account (6) $-\alpha_{\text {in }}^{\max }=1 / \sqrt{7}=0,378 ; \beta_{\text {in }}^{\max }=1 / \sqrt{7}=0,378$.

On the basis of the above gradation of the levels of the performance and availability coefficients being evaluated and taking into account their complexity, these parameters can be determined by the following formulas:

$$
\begin{aligned}
& \beta_{i n}=\left(\beta_{i n}^{1}+\beta_{i n}^{2}+\ldots+\beta_{i n}^{m}\right) / m \\
& \alpha_{i n}=\left(\alpha_{i n}^{1}+\alpha_{i n}^{2}+\alpha_{i n}^{3}\right) / m
\end{aligned}
$$

where $i$ is the constituent reference number; $n$ is the function reference number; $m$ is the number of the parameters.
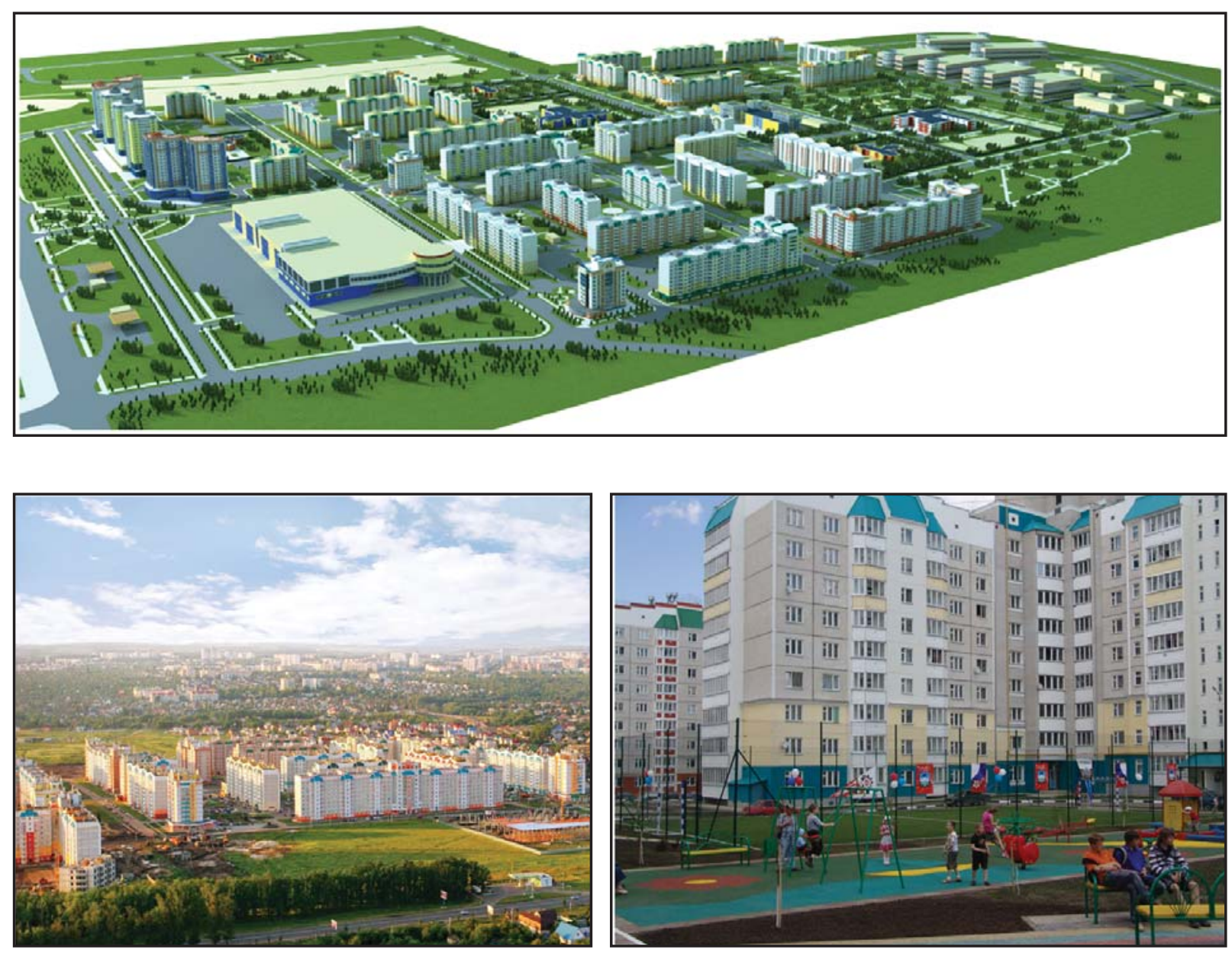

Figure 1: Urban residential district view and infrastructure 
Table 1: Systematization of the constituents of the city infrastructure $i$ when implementing city functions $\Phi n$

\begin{tabular}{|c|c|c|c|c|c|}
\hline \multicolumn{6}{|c|}{ CONSTITUENTS Cin } \\
\hline \multicolumn{6}{|c|}{$\Phi_{1}:$ Life support } \\
\hline $\begin{array}{l}\text { Residential } \\
\text { houses }\end{array}$ & $\begin{array}{l}\text { Chemist's and } \\
\text { health care } \\
\text { institutions }\end{array}$ & $\begin{array}{l}\text { Banks and } \\
\text { ATMs }\end{array}$ & $\begin{array}{l}\text { Food and } \\
\text { non-food stores }\end{array}$ & $\begin{array}{l}\text { Communication } \\
\text { services }\end{array}$ & $\begin{array}{l}\text { Transportation } \\
\text { services }\end{array}$ \\
\hline \multicolumn{6}{|c|}{$\boldsymbol{\Phi}_{2}:$ Entertainment and recreation } \\
\hline Cafes & estaurants & \multicolumn{2}{|c|}{ Fitness and sport facilities } & \multicolumn{2}{|c|}{ Leisure and recreation facilities } \\
\hline \multicolumn{6}{|c|}{$\Phi_{3}:$ Authorities } \\
\hline Adminis & on building & \multicolumn{2}{|c|}{ Police offices } & \multicolumn{2}{|c|}{ Post offices } \\
\hline \multicolumn{6}{|c|}{$\Phi_{4}:$ Mercy } \\
\hline $\begin{array}{l}\text { Struct } \\
\text { for dis }\end{array}$ & $\begin{array}{l}\text { solutions } \\
\text { d people }\end{array}$ & \multicolumn{2}{|c|}{$\begin{array}{l}\text { State programs for providing as- } \\
\text { sistance to certain categories of } \\
\text { citi-zens, social support funds }\end{array}$} & \multicolumn{2}{|c|}{$\begin{array}{c}\text { One off events organized by } \\
\text { authorities and business entities } \\
\text { to support people with limited } \\
\text { mobility }\end{array}$} \\
\hline \multicolumn{6}{|c|}{$\boldsymbol{\Phi}_{5}:$ Knowledge } \\
\hline Presch & nstitutions & \multicolumn{2}{|c|}{$\begin{array}{l}\text { Institutions of second-ary general } \\
\text { education }\end{array}$} & \multicolumn{2}{|c|}{$\begin{array}{l}\text { Institutions of secondary profes- } \\
\text { sional and higher education }\end{array}$} \\
\hline \multicolumn{6}{|c|}{$\Phi_{6}:$ Creative activities } \\
\hline \multicolumn{2}{|c|}{ Music and art schools, workshops } & \multicolumn{2}{|c|}{ Culture and art centres } & \multicolumn{2}{|c|}{ Museums, theatres } \\
\hline \multicolumn{6}{|c|}{$\boldsymbol{\Phi}_{7}:$ Interaction between a human being and nature } \\
\hline \multicolumn{3}{|c|}{$\begin{array}{c}\text { Natural landscapes, skeletons and recreation areas } \\
\text { and processes of regeneration and restoration of } \\
\text { natural environment with the participation of the } \\
\text { society }\end{array}$} & \multicolumn{3}{|c|}{$\begin{array}{l}\text { Natural resources consumption and pollution of the } \\
\text { environment }\end{array}$} \\
\hline
\end{tabular}

The coefficients obtained on the basis of the gradation depending on the contribution of constituent 'Residential houses' $C_{1}$ are given in Tables 2 and 3.

Similarly, based on the gradation, the values of the performance and availability coeffi-cients depending on other constituents for all biosphere compatible city functions were calculat-ed.

Function 'Life Support' $\Phi 1$

\section{Constituent 'Residential houses' C1}

Since all the $i$-constituents of each $\Phi_{n}{ }^{\text {th }}$ function of a biosphere compatible city are eq-uisignificant, then $a_{i, 1}^{*}=a_{i, 1}=0.167, i_{1}=6$.

The integrated indicator of this constituent when performing the city function under study taking into account its contribution is comprised of the equality of the individual indicators taking into account their significance:

$$
\begin{aligned}
& \beta_{1,1}=\left(\beta_{1,1}^{1}+\beta_{1,1}^{2}+\beta_{1,1}^{3}+\beta_{1,1}^{4}+\beta_{1,1}^{5}+\beta_{1,1}^{6}+\beta_{1,1}^{7}\right) / 7= \\
& =(0.283+0.113+0.113+0.094+0.378+0.076+0.076) / 7= \\
& =0.162
\end{aligned}
$$

Availability coefficient is $\alpha_{11}=\left(\alpha_{11}^{1}+\alpha_{11}^{2}\right) / 2=(0.151+0.075) / 2=0.113$. Function 'Entertainment and recreation' $\Phi 2$, $a_{i, 2}^{*}=a_{i, 2}=0.333, i_{2}=3$.

Constituent 'Cafes and restaurants' $\mathrm{C1}$

The integrated indicator of this constituent when performing the city function under study taking into account its contribution is comprised of the equality of the individual indicators taking into account their significance:

$\beta_{1,2}=(0.038+0.038) / 2=0.038$

Availability coefficient is

$\alpha_{1,2}=(0.151+0.075+0.075) / 3=0.100$.

Function 'Authorities' $\Phi 3, i_{3}=3, a_{i, 3}{ }^{*}=a_{i, 3}=0.333$.

Constituent 'Police offices' $\mathrm{C2}$

Coefficient of performance is

$\beta_{2,3}=(0+0.076) / 2=0.038$.

Availability coefficient is

$\alpha_{2,3}=(0.151+0.113) / 2=0.132$ 
Table 2: Evaluation of the performance of function 'Life support' $\Phi_{1}$ in accordance to constituent 'Residential houses' $C_{1}(i=1, n=1)$

\begin{tabular}{|c|c|c|c|c|c|}
\hline $\begin{array}{l}\text { Level of housing } \\
\text { provision } \beta_{1,1}^{1}\end{array}$ & $\begin{array}{c}\text { provision up to } \\
10 \% \text { is } 0\end{array}$ & $\begin{array}{l}\text { provision up to } \\
25 \% \text { is } 0.094\end{array}$ & $\begin{array}{l}\text { provision up to } 50 \% \\
\text { is } \mathbf{0 . 1 8 9}\end{array}$ & $\begin{array}{c}\text { provision up } \\
\text { to } 75 \% \text { is } \\
\mathbf{0 . 2 8 3}\end{array}$ & $\begin{array}{c}\text { provision up } \\
\text { to } 100 \% \text { is } \\
\mathbf{0 . 3 7 8}\end{array}$ \\
\hline $\begin{array}{l}\text { Level of technical } \\
\text { condition } \beta_{1,1}^{2}\end{array}$ & low level is 0 & $\begin{array}{l}\text { average level } \\
\text { is } \mathbf{0 . 0 3 8}\end{array}$ & $\begin{array}{l}\text { level higher than } \\
\text { average is } \mathbf{0 . 0 7 6}\end{array}$ & \multicolumn{2}{|c|}{ high level is $\mathbf{0 . 1 1 3}$} \\
\hline House lifespan $\beta_{1,1}^{3}$ & $\begin{array}{c}\text { long lifespan (up } \\
\text { to } 100 \% \text { from life } \\
\text { utili-ty) is } 0\end{array}$ & $\begin{array}{l}\text { higher than } \\
\text { aver-age } \\
\text { (up to } 75 \% \\
\text { from life utility) } \\
\text { is } \mathbf{0 . 0 3 8}\end{array}$ & $\begin{array}{c}\text { average } \\
\text { (up to } 50 \% \text { from life } \\
\text { utility) is } \mathbf{0 . 0 7 6}\end{array}$ & \multicolumn{2}{|c|}{$\begin{array}{c}\text { short (up to } 25 \% \text { from life } \\
\text { utility) is } \mathbf{0 . 1 1 3}\end{array}$} \\
\hline $\begin{array}{c}\text { Panel-brick houses } \\
\text { ratio } \beta_{1,1}^{4}\end{array}$ & $100: 0 \%$ is 0 & $\begin{array}{c}70: 30 \% \text { is } \\
\mathbf{0 . 0 9 4}\end{array}$ & $50: 50 \%$ is $\mathbf{0 . 1 8 9}$ & $\begin{array}{c}20: 80 \% \text { is } \\
\mathbf{0 . 2 8 3}\end{array}$ & $0 \%$ is $\mathbf{0 . 3 7 8}$ \\
\hline $\begin{array}{l}\text { Houses with their } \\
\text { own boiler-house } \\
\beta_{1,1}^{5}\end{array}$ & $\begin{array}{l}\text { provision up to } \\
25 \% \text { is } 0.094\end{array}$ & $\begin{array}{l}\text { provision up to } \\
50 \% \text { is } \mathbf{0 . 1 8 9}\end{array}$ & $\begin{array}{l}\text { provision up to } 75 \% \\
\text { is } \mathbf{0 . 2 8 3}\end{array}$ & \multicolumn{2}{|c|}{$\begin{array}{c}\text { provision up to } 100 \% \text { is } \\
\mathbf{0 . 3 7 8}\end{array}$} \\
\hline $\begin{array}{l}\text { Level of standard- } \\
\text { ized houses } \beta_{1,1}^{6}\end{array}$ & high level is 0 & $\begin{array}{l}\text { level higher } \\
\text { than average } \\
\text { is } \mathbf{0 . 0 3 8}\end{array}$ & $\begin{array}{c}\text { average level is } \\
0.076\end{array}$ & \multicolumn{2}{|c|}{ low level is $\mathbf{0 . 1 1 3}$} \\
\hline $\begin{array}{l}\text { Level of structure de- } \\
\text { fects revealed when } \\
\text { commissioning } \beta_{1,1}^{7}\end{array}$ & high level is 0 & $\begin{array}{l}\text { level higher } \\
\text { than average } \\
\text { is } \mathbf{0 . 0 3 8}\end{array}$ & $\begin{array}{c}\text { average level is } \\
\mathbf{0 . 0 7 6}\end{array}$ & \multicolumn{2}{|c|}{ low level is $\mathbf{0 . 1 1 3}$} \\
\hline
\end{tabular}

Table 3: Evaluation of availability parameters ( $i=1, n=1)$

\begin{tabular}{|c|c|c|c|c|}
\hline $\begin{array}{l}\text { Spatial availability } \\
\quad \text { limitation } \alpha_{1,1}^{1}\end{array}$ & $\begin{array}{c}\text { no spatial } \\
\text { availability - } 0\end{array}$ & $\begin{array}{c}\text { spatial availability } \\
\text { is possible but pro- } \\
\text { hibited }-\mathbf{0 . 0 3 7}\end{array}$ & $\begin{array}{l}\text { spatial availability } \\
\text { is limited } \mathbf{- 0 . 0 7 5}\end{array}$ & $\begin{array}{c}\text { free spatial } \\
\text { availability - } \\
\mathbf{0 . 1 5 1} \\
\end{array}$ \\
\hline $\begin{array}{l}\text { Personal availability } \\
\quad \text { limitation } \alpha_{2,1}^{2}\end{array}$ & $\begin{array}{c}\text { not avail- } \\
\text { able for all } \\
\text { city-dwellers } \\
-0\end{array}$ & $\begin{array}{l}\text { availability is limit- } \\
\text { ed, it is affordable } \\
\text { for city-dwellers } \\
\text { with high income } \\
\quad-0.037\end{array}$ & $\begin{array}{l}\text { availability is } \\
\text { lim-ited, it is } \\
\text { affordable for } \\
\text { city-dwellers } \\
\text { with an average } \\
\text { income - } \mathbf{0 . 0 7 5}\end{array}$ & $\begin{array}{c}\text { availability is } \\
\text { af-fordable for all } \\
\text { city-dwellers - } \\
\mathbf{0 . 1 1 3}\end{array}$ \\
\hline
\end{tabular}

Function 'Mercy' $\Phi 4, i_{4}=3, a_{i 4}^{*}=a_{i, 4}=0.333$.

Constituent 'Structural solutions for disabled people' C1 Coefficient of performance is

$\beta_{1,4}=(0.113+0.265+0.038) / 3=0.139$.

Availability coefficient is

$\alpha_{1,4}=(0.151+0.113+0.075) / 3=0.113$.

Function 'Knowledge' $\Phi 5, i_{5}=3, a_{i, 5}^{*}=a_{i, 5}=0.333$.

Constituent 'Preschool institutions' C1

Coefficient of performance is

$\beta_{1,5}=(0.094+0.189+0.076) / 3=0.119$.
Availability coefficient is

$\alpha_{1,5}=(0.151+0.113+0.076) / 3=0.113$.

Function 'Creative activities' $\Phi 6, i_{6}=3$,

$a_{i, 6}^{*}=a_{i, 6}=0.333$.

Constituent 'Culture and art centres' C2

Coefficient of performance is

$\beta_{2,6}=(0+0+0.265) / 3=0.088$.

Availability coefficient is

$\alpha_{2,6}=(0.151+0.038+0.037) / 3=0.075$.

Function 'Interaction between a human being and nature' $\Phi 7, i_{7}=2, a_{i, 7}^{*}=a_{i, 7}=0.50$. 
Constituent 'Natural landscapes, skeletons and recreation areas and processes of re-generation and restoration of natural environment with the participation of the society' C1

Coefficient of performance is

$\beta_{1,7}=(0.038+0.076+0.265) / 3=0.126$.

Availability coefficient is

$\alpha_{1,7}=(0.076+0.113+0.037) / 3=0.076$.

As a result, the indicators of the performance of each biosphere compatible city func-tion were determined (by the example of one of the new residential districts in the city of Orel). The results of the calculation are summarized in Table 4.

Figure 2 shows a diagram of the numerical distribution of the contribution of the infra-structure constituents of the residential district of Orel city to the performance of biosphere compatible city functions. The area of the indicators rational values includes the concept of ra-tional needs of the population determining the conditions for safe and comfortable living.

The analysis of the diagram of the numerical distribution of the contribution of the con-stituents to the performance of the biosphere compatible city functions by the example of the residential district under consideration has shown the following facts.

For the function 'Life support', the indicator of performance equals $62 \%$ the maximum possible value. This figure is mostly comprised of the new constructed buildings (square meters). In general, the indicator, commensurable with affordable housing, has an average value for all-Russian standards. Nevertheless, housing problem as a whole remains unsolved. The quality of the housing and the living conditions, especially from the standpoint of modern requirements of green standards, resource and energy conservation, and waste disposal leave much to be desired.

The indicator of performance of the function 'Entertainment and Recreation' equals $29 \%$ the possible. This suggests that there are not enough affordable facilities for recreation and entertainment for the population within the limits of the residential district under study. Currently, there are no leisure and recreation or fitness and sport facilities. In view of sociologists, this is a very dangerous trend, since there is a cause and effect relationships between the quality of the organization of urban environment and the deviant behavior of urban dwellers [07].

The indicator of performance of the function 'Authorities' equals $20 \%$ the possible val-ue. This is due to the lack of a police station in this residential district and the poor work of the local police inspector. Growing social inequality and property stratification of Russian society, confrontation of cultures, and decline in the level of education create an extremely tense situa-tion in such living conditions. A poorly administered residential district, and in the future, a city, is able to quickly destroy the surrounding natural environment and will keep itself (the city) on a 'starvation diet' because of absence of natural resources [08]. The way out of this situation is to create real mechanisms and legislative framework for regulating relations in the environment-human system and to form conditions for the development of human potential on this basis as soon as possible.

The indicator of performance of the function 'Mercy' is $76 \%$ of the possible one. This value is sufficiently high only due to the implementation of constructive measures for disabled people (ramps, parking lots for the disabled, spacious elevators, etc.) in accordance with the current regulations. Despite this, the quality of some constructive solutions does not correspond to regulation values, which creates obstacles for disabled people's comfortable living. Developed architectural and planning solutions based on the requirements of the concept of technical regulation and the current regulatory framework are still mostly declarative although they are aimed at creating an accessible 'barrier-free' environment [09].

The indicator of performance of the function 'Knowledge equals $36 \%$ the possible val-ue. A low percentage is due to the lack of the educational institutions which had to be built ac-cording to the project. Currently, there is only one kindergarten and a school is at the stage of construction. Moreover, residential houses are being built on the site of the other projected schools and kindergartens to obtain more flats (square meters).

The indicator of performance of the function 'Creativityy activities' is $28 \%$ of the pos-sible one. The low value of the indicator shows that there are no both culture and art centres within the territory of the district and museums and theatres situated close to it. The existing practice of developing residential housing to achieve the target indicators of city functions is not aimed at satisfying rational human needs through a creative constituent but is reduced only to meeting individual demand for goods and services. Theaters and conservatories, concert halls and museums not only define an attractive architectural appearance but also give the city its internal importance and determine its potential for further development.

The indicator of performance of the function 'Interaction between a human being and nature' equals $50 \%$ the possible value. This figure indicates the ongoing landscaping and amenities improvement taking place on the streets of the district; however, these actions are not sufficient for comfortable living. The residents of the district are often concerned about fumes and unpleasant smell that spreads throughout the area because local treatment facilities do not operate properly. The problem of sludge utilization after wastewater treatment at these treatment facilities has not been solved. This means that the principles of compatibility with the natural environment are not taken into account at the stage of designing and construction of modern residential districts. Moreover, natural conditions, in addition to the function of beautifying, pro-vide the main base on which all the life support of a city is built. 
Table 4: The values of biosphere compatible city functions performance indicators $\xi_{\Phi_{n}}$ (based on the results of aggregated evaluation)

\begin{tabular}{|c|c|}
\hline City functions and their constituents & $\begin{array}{l}\text { Values of city functions performance } \\
\text { indicator } \xi_{\Phi_{n}}\end{array}$ \\
\hline $\boldsymbol{\Phi}_{1}$ : Life Support; $\boldsymbol{C}_{1}-$ Residential houses & 0.018 \\
\hline $\boldsymbol{\Phi}_{2}$ : Entertainment and recreation; $\boldsymbol{C}_{1}-$ Cafes and restaurants & 0.004 \\
\hline $\boldsymbol{\Phi}_{3}:$ Authorities; $\boldsymbol{C}_{2}-$ Police offices & 0.005 \\
\hline $\boldsymbol{\Phi}_{4}:$ Mercy; $\boldsymbol{C}_{1}-$ Structural solutions for disabled people & 0.016 \\
\hline$\Phi_{5}:$ Knowledge; $\boldsymbol{C}_{1}-$ Preschool institutions & 0.013 \\
\hline $\boldsymbol{\Phi}_{6}:$ Creative activities; $\boldsymbol{C}_{2}-$ Culture and art centres & 0.007 \\
\hline $\begin{array}{c}\Phi_{7} \text { : Interaction between a human being and nature; } \boldsymbol{C}_{1}-\text { Natural land- } \\
\text { scapes, skeletons and recreation areas and processes of regeneration } \\
\text { and restoration of natural environment with the participation of the } \\
\text { society }\end{array}$ & 0.009 \\
\hline
\end{tabular}

_ maximum possible value of the indicator of the city function performance

actual value of the indicator of the city function performance

maximum admissible value of the comfort state parameters

minimum admissible value of the comfort state parameters

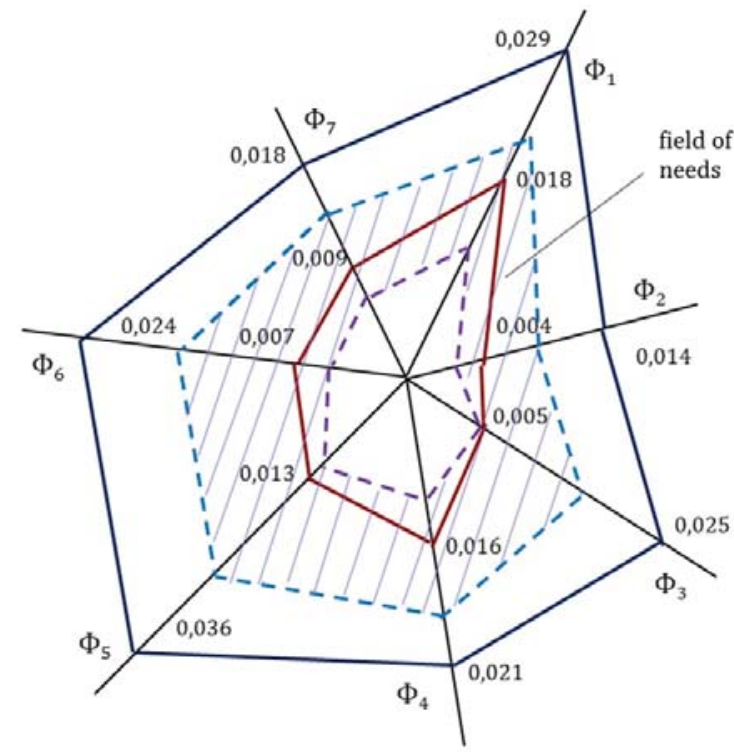

field of rational human

$\Phi_{1}$ - Life Support

$\Phi_{2}$ - Entertainment and recreation

$\Phi_{3}$ - Authorities

$\Phi_{4}$ - Mercy

$\Phi_{5}$ - Knowledge

$\Phi_{5}$ - Knowledge

$\Phi_{6}$ - Creative activities

$\Phi_{7}$ - Interaction between a human being and nature

Figure 2: Diagram of the numerical distribution of the contribution of the infrastructure constituents of Orel residential district to the performance of biosphere compatible city functions

\section{CONCLUSIONS}

As a result, the analysis of the numerical distribution of the contribution of the constituents to the performance of biosphere compatible city functions by the example of a single residential district showed low performance of most of city functions. Target indicators of achieving such functions as 'Mercy', "Creative activities' 'Interaction between a human being and nature' are not planned at all in the design solutions of modern housing.

This problem has system nature. In recent years, many new residential districts the main indica-tor for which is the number of square meters of housing on the built-up area even to the detri-ment of social infrastructure facilities and violation of the regulations concerning recreation areas have been built in many cities of Russia. The problem of intellectual development of the pop-ulation of modern residential areas also remains unsolved. Ecological situation in these areas is far from satisfactory.

From the standpoint of the biosphere compatibility of a settlement, the existing problems should be solved through the development of urbanized areas in relation- 
ship with nature. This thesis will allow forming scientifically-based city-planning policy and carry out design and construction of urban infrastructure according to the principles of self-regulation and rethinking public interests. In the future, this will help create a full-fledged socio-psychological, architecturally expressive living environment that ensures social stability, humanistic orientation of market relations, safety and quality of living for population of modern cities.

\section{REFERENCES}

1. Ilyichev, V. A. Principles of Transforming a City into a Biosphere Compatible City Developing a Human Being [Text] / V. A. Ilyichev // Scientific, Technical and Industrial Magazine "Industrial and Civil Engineering". - M .: OOO "Izdatelstvo PGS", 2010. - No 6. - P. $3-13$.

2. Ilyichev, V. A. Can a City be a Biosphere Compatible One and Develop a Human Being? [Text] / V. A. Ilyichev // Architecture and Construction of Moscow. - 2009. - No. 2 (544). - P. 8 -13.

3. Ilyichev, V. A. Proposals to the Doctrine of Urban Planning and Rehousing (Strategic Planning of Cities) [Text] / V. A. Ilyichev, A. M. Karimov, V. I. Kolchunov, V. V. Aleksashina, N. V. Bakae-va, S. A. Kobeleva // Housing Construction. - M., 2012. - No 1. - P. 2 - 11.

4. Ilyichev, V. A. Some Issues of Settlement Design from the Perspective of the Concept of Bio-sphere Compatibility [Text] / V. A. Ilyichev, V. I. Kolchunov, A. V. Bersenev, A. L. Pozdnyakov. - Academia, 2009. No 1. - P. 50 - 57.
5. Bakaeva, N. V. A Technique for Calculating General Criteria of Evaluating the State of a Ter-ritorial Autonomous Transport System Based on the Concept of Biosphere Compatibility [Text] / N. V. Bakaeva, I. V. Shishkina // Academia. Architecture and Construction, 2011. - No 4. - P. 112 - 117.

6. Bakaeva, N. V. Evaluation of the Contribution of Transport Infrastructure to the Performance of Biosphere Compatible City Functions [Text] / N. V. Bakaeva, I. V. Shishkina // Urban Plan-ning, 2012. - No $1 / 17 .-$ P. 51 - 59.

7. Kudryavtsev, A. P. Urban Planning: Main Issues [Text] / A. P. Kudryavtsev, Yu. A. Sdobnov // Housing Construction. - 2008. - No. 3. - P. 2 - 3.

8. Ilyichev, V. A. Innovative Practices in Cities and the Doctrine of Urban Planning [Text] / V. A. Ilyichev, S. G. Emelyanov, V.I. Kolchunov, N. V. Bakaeva // Biosphere Compatibility: A Human Being, a Region, Technologies, 2014. - No 3 (7). - P. 3 - 18.

9. Ilyichev, V. A. Social Expectations, Housing Programs and Quality of Life in Urban Areas [Text] / V. A. Ilyichev, S. G. Emelyanov, V. I. Kolchunov, N. V. Bakaeva // Industrial and Civil Engineering. - M., 2014. - No. 1. - C.3 - 7 . 